\title{
IL-22 exacerbates the severity of CVB3-induced acute viral myocarditis in IL-17A-deficient mice
}

\author{
QING KONG*, YIMIN XUE*, WEIFENG WU, FAN YANG, YANLI LIU, \\ MENGSHA GAO, WENYIN LAI and XIAOFEN PAN \\ Department of Cardiology, the First Affiliated Hospital of Guangxi Medical University, \\ Guangxi Cardiovascular Institute, Nanning, Guangxi 530021, P.R. China
}

Received November 20, 2012; Accepted January 31, 2013

DOI: $10.3892 / \mathrm{mmr} .2013 .1323$

\begin{abstract}
Interleukin (IL)-22 has either proinflammatory or tissue-protective properties, depending on the nature of the affected tissue and the local cytokine milieu, including the presence or absence of IL-17A co-expression. We have previously demonstrated that IL-22 has critical antiinflammatory and antiviral roles in mice with coxsackievirus B3 (CVB3)-induced acute viral myocarditis (AVMC) in the presence of IL-17A. However, whether IL-17A determines the function of IL-22 in AVMC remains unknown. Therefore, the present study, in continuation of our previous investigations, aimed to determine whether IL-22 plays a distinctly different role in the absence of IL-17A in AVMC by using IL-17Adeficient mice. Results demonstrated that the neutralization of IL-22 in IL-17A-deficient mice alleviated the severity of myocarditis. This was demonstrated by the lower pathological scores of heart sections and ratios of heart weight/ body weight (HW/BW), reduced production of activator of transcription 3 (STAT3) and proinflammatory cytokines TNF- $\alpha$ and IL- 6 , followed by increased viral replication and decreased levels of the antiviral cytokine IFN- $\gamma$. Furthermore, the correlation between cardiac CVB3 RNA and IL-22 mRNA or IFN- $\gamma$ mRNA was negative. In conclusion, IL-22 exacerbated the severity of AVMC and restrained viral replication in the absence of IL-17A. Spleen lymphocytes cultured with recombinant IL-17 (rIL-17) increased the production of IL-22. Combined with our previous data, these results indicate that IL-17A is not involved in regulating the antiviral role,
\end{abstract}

Correspondence to: Professor Weifeng Wu, Department of Cardiology, the First Affiliated Hospital of Guangxi Medical University, Guangxi Cardiovascular Institute, Shuang-Yong Road 6, Nanning, Guangxi 530021, P.R. China

E-mail:wucna@yahoo.com.cn

${ }^{*}$ Contributed equally

Key words: interleukin-22, interleukin-17A, acute viral myocarditis, antiviral, proinflammatory, anti-inflammatory however, may mediate the tissue-protective versus pathogenic properties of IL-22 in CVB3-induced AVMC in mice.

\section{Introduction}

Acute viral myocarditis (AVMC) is characterized by virus-triggered myocardial inflammation, followed by an autoimmune response, and leads to a significant minority of dilated cardiomyopathy (DCM) cases (1). Myocarditis causes 4-20\% of sudden cardiovascular-associated deaths among young adults, the military and athletes (2).Viral infections, including coxsackievirus B3 (CVB3), are the most commonly identified cause of myocarditis in developed countries and are able to induce myocarditis and DCM in animal models $(2,3)$. An excessively activated immune response triggered by the virus was considered to be the dominant cause of myocyte injury in AVMC, particularly T-cell activation and the secretion of numerous proinflammatory/protective cytokines. Cytokine-based therapy has been considered an important strategy in the treatment of AVMC (4-6). Recently, identification of the interleukin (IL)-23/Th17 axis in the pathophysiology of AVMC has shifted the cytokine paradigm from Th1 to Th17 cytokines and is mainly focused on IL-17A $(5,6)$.

IL-17A, a cytokine predominantly produced by Th17 cells, was identified as important in the pathogenesis of AVMC. The critical proinflammatory role of this cytokine and its contribution to CVB3 replication in AVMC is well documented $(5,6)$. IL-22, a member of the IL-10 family of cytokines, has received increasing amounts of attention and is currently widely investigated. IL-22 is an important cytokine, derived from multiple cells of the innate and adaptive immune system, including but not limited to Th22, Th1 and Th17 and CD $8^{+} \mathrm{T}$, $\gamma \delta \mathrm{T}$ and NK cells $(7,8)$. IL-22 stimulation of IL-22 receptorexpressing cells results in the activation of its downstream signals, including signal transducers and activator of transcription 3 (STAT3) signaling pathways, namely the IL-22/STAT3 pathway (8-10). A large number of murine and human studies have demonstrated that IL-22 provides a unique contribution to tissue inflammation, immune responses and viral infection and has proinflammatory and tissue-protective properties, depending on the context in which it is expressed (8,11-13). In different stages of disease development, IL-22 has shown opposing short- and long-term effects $(14,15)$. The biological 
activities of IL-22 are complex and this has caused it to be described as 'a sheep in wolf's clothing' (16). Furthermore, IL-22 is involved in IL-17-mediated diseases and the signaling pathways of these two cytokines may synergize to induce the expression of anti-inflammatory factors (8-16). More specifically, the proinflammatory properties and tissue-protective functions of IL-22 were regulated by IL-17A in airway damage and inflammation (17). These data indicate that the differential temporal and spatial co-expression of IL-17A and IL-22 may underlie the conflicting results for the biological effects of IL-22 in distinct disease models. This may offer selective therapeutic potential in the treatment of IL-17A and IL-22-associated inflammatory diseases.

IL-22 has been considered an ideal therapeutic candidate since it specifically affects tissue responses without having direct effects on the immune response (8). Our previous study conducted on wild-type (WT) mice demonstrated the existence of a specific pattern of IL-22 cytokines in CVB3-induced AVMC (18). Furthermore, neutralization of IL-22 in vivo exacerbated the severity of AVMC and promoted cardiac viral replication, which highlights the anti-inflammatory and antiviral roles of IL-22 in the pathogenesis of myocarditis in the presence of IL-17A. However, whether IL-17A contributes to the tissue-protective role of IL-22 in the development of AVMC remains to be elucidated. The present study, in continuation of our previous investigations, aimed to determine whether IL-22 plays a distinctly different role in the absence of IL-17A in AVMC by using IL-17A-deficient mice (IL-17A ${ }^{-/}$).

\section{Materials and methods}

Mice. Specific pathogen-free male IL-17A-deficient mice on the BALB/c background (designated in the present study as IL-17A ${ }^{-/}$), aged 6 weeks, were provided by Dr Yoichiro Iwakura (Center for Experimental Medicine and Systems Biology, the Institute of Medical Science, the University of Tokyo, Tokyo, Japan) (19). All animals were kept in a pathogen-free mouse room in the Experimental Animal Center (Guangxi Medical University, Nanning, China). Experiments were carried out in accordance with protocols approved by the Guangxi Medical University Animal Ethics Committee.

Virus. CVB3 (Nancy strain from the Institute of Immunology of Guangxi Medical University) was maintained by passage through HEp-2 cells. A plaque-forming unit (PFU) assay was used to determine that the virus titer was $1 \times 10^{8}$. CVB3 was diluted in PBS (Solarbio Science \& Technology Co., Ltd., Beijing, China). BALB/c mice were infected by an intraperitoneal injection (i.p.) of $100 \mu \mathrm{l}$ PBS containing $\sim 10^{6}$ PFU CVB3 to establish the AVMC models.

Neutralization of $I L-22$ in $I L-17 A^{-/-}$mice. For in vivo IL-22

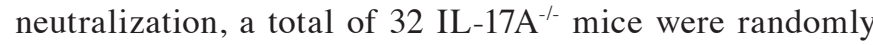
divided into four groups: Mice in the AVMC group were injected with CVB3 and PBS (50 $\mu \mathrm{g}$ per mouse, $\mathrm{n}=8$ ); in the anti-IL-22 Ab group, mice were administered with CVB3 and anti-IL-22 Ab (AF582; $50 \mu \mathrm{g}$ per mouse; R\&D Systems, Inc., Minneapolis, MN, USA; $n=8)$; IgG control group, mice were injected with CVB3 and normal IgG control (AB-108-C; $50 \mu \mathrm{g}$ per mouse; R\&D Systems; $\mathrm{n}=8)$; and in the normal group, IL-17A $\mathrm{A}^{-/-}$mice received no treatments $(\mathrm{n}=8)$. The day of intraperitoneal injection was defined as day 0 . All surviving animals were sacrificed on day 14 after CVB3 infection. The ratios for heart weight/body weight (HW/BW) were recorded. Blood was collected and the serum was prepared for analysis. Hearts and spleens were removed aseptically as fresh specimens for analysis.

Histopathology. The ventricular tissues of the hearts were fixed in $10 \%$ formalin and embedded in paraffin. After the entire length of the heart was sectioned $(5 \mu \mathrm{m})$ and stained with hematoxylin and eosin (H\&E), histopathological changes were observed using light microscopy (Nikon Eclipse E800 Microscope, Kawasaki, Kanagawa, Japan). The pathological scores of heart tissues were graded as follows: a score of 0 was assigned for no inflammatory infiltrates, 1 for a small foci of inflammatory cells between myocytes or inflammatory cells surrounding individual myocytes, 2 for a larger foci of 100 inflammatory cells or involving at least 30 myocytes, 3 when $10 \%$ of a myocardial cross-section was involved or 4 if $30 \%$ of a myocardial cross-section was involved (20). The assessment was separately scored by two independent pathologists in a blinded manner.

Preparation of spleen lymphocytes and cell cultures. Spleens from AVMC mice were collected aseptically. After mincing, splenic cells were gently dispersed through a nylon mesh into a single-cell suspension. The lymphocyte fractions of the splenic mononuclear cell suspensions were obtained by Ficoll-Paque (Solarbio Science \& Technology Co., Ltd.) gradient centrifugation and washed twice with PBS. Lymphocytes from each spleen were divided into 2 groups and cultured in a total volume of $300 \mu \mathrm{l}$ for $48 \mathrm{~h}$ in triplicate wells $\left(5 \times 10^{5}\right.$ cells/well) of a 96-well culture plate, in RPMI-1640 supplemented with penicillin $(100 \mathrm{U} / \mathrm{ml})$, streptomycin $(100 \mu \mathrm{g} / \mathrm{ml}), 10 \%$ fetal bovine serum (Gibco-BRL, Carlsbad, CA, USA) and phytohaemafflutinin (PHA; $10 \mu \mathrm{g} / \mathrm{ml}$; Sigma-Aldrich, St. Louis, MO, USA) at $37^{\circ} \mathrm{C}$ and $5 \% \mathrm{CO}_{2}$, in the absence or presence of the recombinant mouse IL-17 (rIL-17; 25 ng/ml; R\&D Systems). Cells were collected and used in real-time polymerase chain reaction (RT-PCR), while the culture supernatants were assayed by ELISA.

Plaque-forming assay. Viral titers were determined using a standard plaque formation assay and results were expressed per organ weight $(\mathrm{g})$. A section of the heart tissue was weighed and homogenized in $2 \mathrm{ml}$ PBS. The supernatant was absorbed and sequentially diluted 10-fold in RPMI-1640 medium after three freeze-thaw cycles and centrifugation at $500 \mathrm{x} \mathrm{g}$ for $10 \mathrm{~min}$. The HeLa cell monolayers were incubated with the supernatant for $1 \mathrm{~h}$ at $37^{\circ} \mathrm{C}$ and $5 \% \mathrm{CO}_{2}$ in six-well plates, washed in PBS and covered with $2 \mathrm{ml}$ of $0.4 \%$ agar, DMEM and $5 \%$ FCS. The monolayers were fixed in paraformaldehyde and stained in crystal violet after cultivation for $72 \mathrm{~h}$ and the number of plaques were counted.

$R T-P C R$. The total RNA of homogenized heart tissue and cellular RNA of the cultured lymphocytes was extracted with TRIzol ${ }^{\circledR}$ reagent (Invitrogen, Carlsbad, CA, USA). Reverse transcription into cDNA was carried out using a Reverse 
Table I. Primer sequences for real-time RT-PCR.

\begin{tabular}{|c|c|}
\hline Molecule & Sequence $\left(5^{\prime}-3^{\prime}\right)$ \\
\hline TNF- $\alpha$ & $\begin{array}{l}\text { Sense: AGTCCGGGCAGGTCTACTTT } \\
\text { Anti-sense: TTGGACCCTGAGCCATAATC }\end{array}$ \\
\hline IL-6 & $\begin{array}{l}\text { Sense: ACAGAAGGAGTGGCTAAGGACC } \\
\text { Anti-sense: TAGGCATAACGCACTAGGTTT }\end{array}$ \\
\hline IL-22 & $\begin{array}{l}\text { Sense: CGATTGGGGAACTGGACCTG } \\
\text { Anti-sense: GGACGTTAGCTTCTCACTTT }\end{array}$ \\
\hline CVB3 & $\begin{array}{l}\text { Sense: CGGTACCTTTGTGCGCCTGT } \\
\text { Anti-sense: CAGGCCGCCAACGCAGCC }\end{array}$ \\
\hline IFN- $\gamma$ & $\begin{array}{l}\text { Sense: CTCAAGTGGCATAGATGTGGAAG } \\
\text { Anti-sense: GCTGGACCTGTGGGTTGTTGA }\end{array}$ \\
\hline STAT3 & $\begin{array}{l}\text { Sense: CCCATATCGTCTGAAACTC } \\
\text { Anti-sense: TTGCTCCCTTCTGCTCT }\end{array}$ \\
\hline$\beta$-actin & $\begin{array}{l}\text { Sense: AATTCCATCATGAAGTGTGA } \\
\text { Anti-sense: ACTCCTGCTTGCTGATCCAC }\end{array}$ \\
\hline
\end{tabular}

IL, interleukin; CVB3, coxsackievirus B3.

Transcription kit (Fermentas, Vilnius, Lithuania), according to the manufacturer's instructions. RT-PCR was performed with an ABI 7500 Sequence Detection System using SYBRGreen (Applied Biosystems, Foster City, CA, USA). An initial denaturation step for $3 \mathrm{~min}$ at $94^{\circ} \mathrm{C}, 35$ cycles of denaturation at $94^{\circ} \mathrm{C}$ for $30 \mathrm{sec}$, annealing at $60^{\circ} \mathrm{C}$ for $30 \mathrm{sec}$ and extension at $72^{\circ} \mathrm{C}$ for $60 \mathrm{sec}$ were carried out. The relative gene expression levels were normalized to the level of $\beta$-actin transcripts and quantified using the $\Delta \Delta C T$ method. Each reaction was carried out in triplicate. Primers for IL-22, IFN- $\gamma$, TNF- $\alpha$, IL-6, CVB3, STAT3 and the housekeeping gene $\beta$-actin were designed by Primer Premier 5.0 (Table I).

Western blot analysis. The total proteins were extracted according to the manufacturer's instructions. Protein concentrations were determined using a BCA protein assay kit (Beyotime Institute of Biotechnology, Shanghai, China). Equal amounts of denatured sample protein $(50 \mu \mathrm{g})$ were separated in $10 \%$ SDS-PAGE gel and transferred onto a nitrocellulose membrane. After blocking with $6 \%$ non-fat dry milk in Tris-buffered saline containing $0.1 \%$ Tween-20, the membranes were treated with anti-phospho-STAT3 (p-Y705-STAT3; 1:12,000; Abcam, Cambridge, MA, USA) and glyceraldehyde phosphate dehydrogenase (GAPDH; 1:10,000; Kang Chen Bio-tech, Shanghai, China) antibodies overnight at $4^{\circ} \mathrm{C}$ and exposed to the corresponding HRP-conjugated goat anti-rabbit IgG (1:5,000; Santa Cruz Biotechnology, Inc., Santa Cruz, CA, USA) for $1 \mathrm{~h}$ at room temperature. Labeled bands were detected using an enhanced chemiluminescence detection kit (BestBio Inc., Shanghai, China) and analyzed using the Image Lab 2.0 analysis system (Bio-Rad Laboratory, Hercules, CA, USA). The intensity of phosphor-STAT3 (p-STAT3) bands was normalized to the levels of GAPDH.

Cytokine assay. ELISA was performed to determine the cytokine content in serum or cell culture supernatants. The Quantikine Mouse IL-22 Immunoassay (Cat. No. 436307,
Biolegend, San Diego, CA, USA) was used to detect the levels of IL-22. The minimal detectable concentration was $5 \mathrm{pg} / \mathrm{ml}$. No cross-reactivity was observed during detection. Samples were measured in triplicate.

Statistical analysis. Data were expressed as the mean \pm standard deviation (SD). For statistical analysis, differences between the mean values were tested by Student's t-test or ANOVA, using SPSS 17.0. Correlations were determined by Spearman's rank correlation coefficients. The Mann-Whitney U test was carried out for the differences between pathological scores. $\mathrm{P}<0.05$ was considered to indicate a statistically significant difference.

\section{Results}

Neutralization of $I L-22$ in $I L-17 A^{-\mu}$ mice alleviated the severity of myocarditis. No mice died in the normal, AVMC, anti-IL-22 Ab or IgG control groups until day 14. With the exception of the normal group, inflammatory cell infiltration or necrotic lesions and visible clinical signs of myocarditis were observed in the AVMC, anti-IL-22 Ab and IgG control groups (Fig. 1A and B). Data showed that injection of IL-22 neutralizing antibodies alleviated the severity of myocarditis. The pathological scores of heart sections from mice receiving anti-IL-22 $\mathrm{Ab}(1.48 \pm 0.18)$ were lower than those in mice in the AVMC (2.12 \pm 0.37$)$ and IgG control $(2.08 \pm 0.29)$ groups (all $\mathrm{P}<0.01)$. Compared with the AVMC and IgG control groups, significantly decreased values for HW/BW were observed in the anti-IL-22 Ab group (Fig. 1C; all $\mathrm{P}<0.01$ ). With regard to the pathological scores and ratios of HW/BW, no significant difference was observed between the AVMC and IgG control groups $(\mathrm{P}>0.05)$.

Neutralization of IL-22 in IL-17A ${ }^{-/-}$mice promoted viral replication. On day 14, the levels of cardiac CVB3 titers (values expressed in PFU/g) were 0 in the normal, $(9.17 \pm 2.22) \times 10^{3}$ in the AVMC, $(1.08 \pm 0.15) \times 10^{5}$ in the anti-IL-22 Ab and $(9.13 \pm 2.30)$ $\mathrm{x} 10^{3}$ in the $\mathrm{IgG}$ control groups. Data revealed that the levels of cardiac viral titers were elevated significantly in the antiIL-22 Ab group compared with the normal, AVMC and IgG control groups (all $\mathrm{P}<0.01$ ). At the same time-point, the relative expression levels of cardiac CVB3 RNA in the anti-IL-22 $\mathrm{Ab}$ group were higher than those in the normal, AVMC and IgG control groups (all $\mathrm{P}<0.01$ ). Cardiac CVB3 RNA was not detected in the normal group. Differences in CVB3 titers and cardiac CVB3 RNA expression levels between the AVMC and IgG control groups were not statistically significant (Fig. 2A and $\mathrm{B})$.

Neutralization of IL-22 in IL-17A ${ }^{-/}$mice decreased the production of TNF- $\alpha, I L-6$ and IFN- $\gamma$. Compared with the normal group, an increased production of TNF- $\alpha$, IL- 6 and IFN- $\gamma$ was observed in the AVMC, IgG control and anti-IL-22 Ab groups (Fig. 2C-E). Compared with the AVMC and IgG control groups, lower expression levels of cardiac TNF- $\alpha$, IL- 6 and IFN- $\gamma$ mRNA were observed in the anti-IL-22 Ab group (all $\mathrm{P}<0.05$ ) on day 14 postinjection. With regard to the levels of TNF- $\alpha$, IL- 6 and IFN- $\gamma$ genes, no significant changes were observed between the AVMC and IgG control groups (all $\mathrm{P}>0.05$ ). It 
A
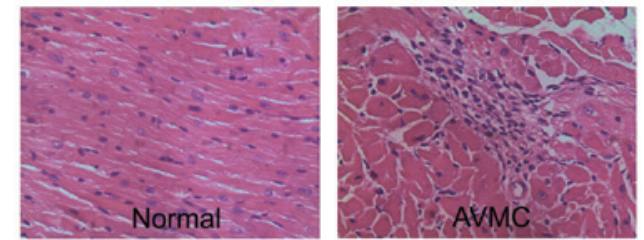

B

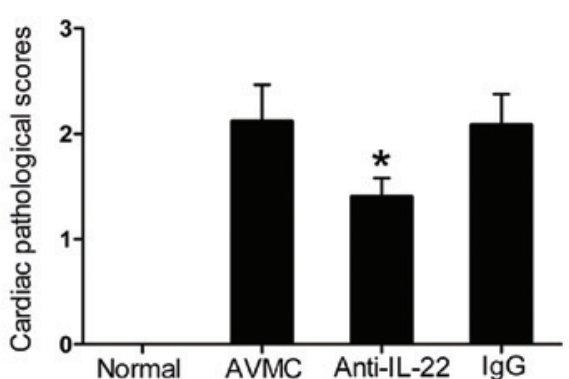

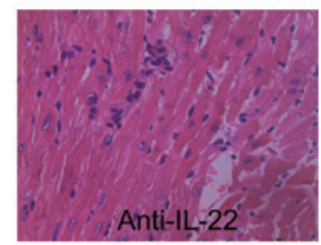

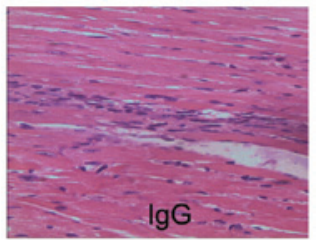

C

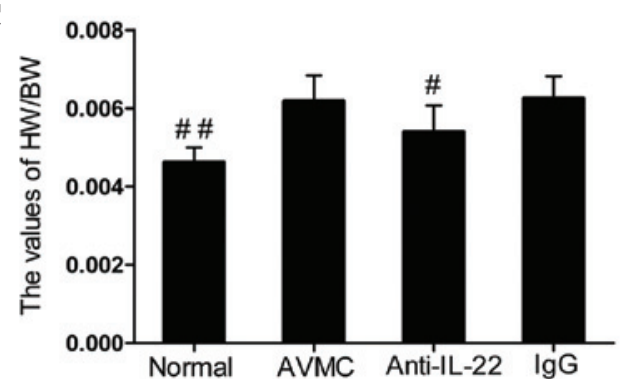

Figure 1. Neutralization of IL-22 in IL-17A $\%$ mice alleviated the severity of myocarditis. (A) Representative histopathological images in heart tissues (H\&E, original magnification $\times 400$ ). (B) The pathological scores in the normal, AVMC, anti-IL-22 Ab and IgG control groups. "P<0.01, versus normal, AVMC and IgG groups. (C) The ratio of HW/BW in different groups. Eight mice in each group were analyzed. ${ }^{~} \mathrm{P}<0.05$ versus the normal, $\mathrm{AVMC}$ and IgG groups. ${ }^{\# \#} \mathrm{P}<0.05$ versus the AVMC, anti-IL-22 and IgG groups. IL, interleukin; AVMC, acute viral myocarditis; H\&E, hematoxylin and eosin; HW/BW, heart weight/body weight.

$$
\text { A }
$$

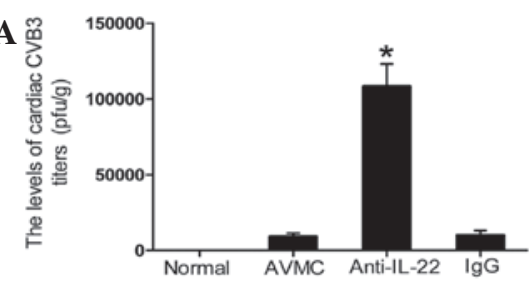

B

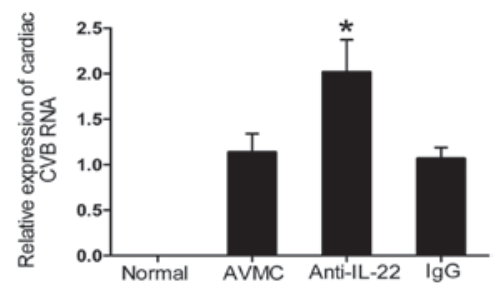

C

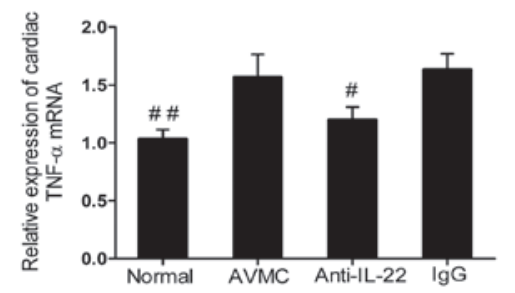

D

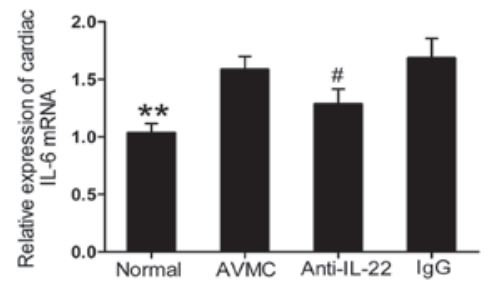

$\mathbf{E}$

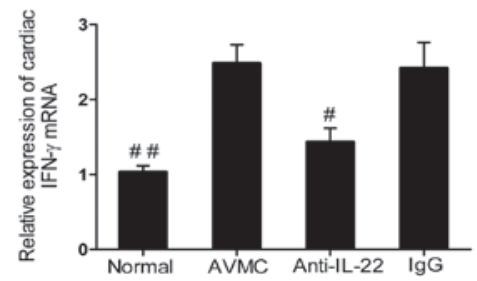

$\mathbf{F}$

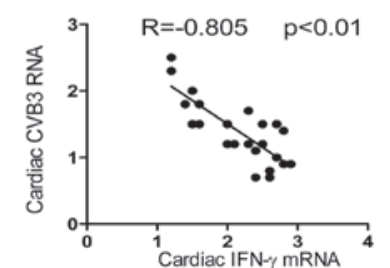

Figure 2. Neutralization of IL-22 in IL-17A $\%$ mice promoted viral replication and decreased the production of TNF- $\alpha$, IL- 6 and IFN- $\gamma$. (A) The levels of cardiac CVB3 titers on day 14. Data show the mean values of CVB3 PFU/g of heart. (B) The relative expression levels of cardiac CVB3 RNA in different groups. (C-E) The result of statistical analysis for the alterations in cardiac TNF- $\alpha$, IL- 6 and IFN- $\gamma$ mRNA, as measured by RT-PCR. (F) The correlation analysis of cardiac CVB3 RNA, cardiac IL-22 mRNA and IFN- $\gamma$ mRNA. Each point represents an individual mouse. " $\mathrm{P}<0.01$ and ${ }^{\text {"P }}<0.05$ versus the normal, AVMC and IgG groups. ${ }^{* *} \mathrm{P}<0.01$ and ${ }^{\# \#} \mathrm{P}<0.05$ versus the AVMC, anti-IL-22 and IgG groups. Values are presented as the mean $\pm \mathrm{SD}$. IL, interleukin; CVB3, coxsackievirus B3; RT-PCR, real-time polymerase chain reaction; AVMC, acute viral myocarditis; SD, standard deviation.

was determined that the cardiac IL-22 mRNA was correlated negatively with the CVB3 RNA ( $\mathrm{R}=-0.805, \mathrm{P}<0.01$; Fig. $2 \mathrm{~F})$.

Neutralization of $I L-22$ in $I L-17 A^{-/-}$mice decreased the levels of IL-22 and STAT3. Compared with the normal group, an increased production of serum IL-22 and cardiac IL-22 mRNA was observed in the AVMC, anti-IL-22 Ab and IgG control groups (all $\mathrm{P}<0.01$; Fig. 3A and $\mathrm{B}$ ). However, compared with the AVMC and IgG control groups, anti-IL-22 Ab markedly decreased the expression levels of circulating IL-22 and cardiac IL-22 (all $\mathrm{P}<0.05)$ on day 14 postinjection. A negative correlation was established between cardiac IL-22 mRNA and CVB3 RNA ( $\mathrm{R}=-0.825, \mathrm{P}<0.01$; Fig. 3C). Furthermore, decreased expression levels of cardiac STAT3 mRNA and p-STAT3, analyzed by RT-PCR and western blot analysis, respectively, were observed in the anti-IL-22 Ab group (all 
A

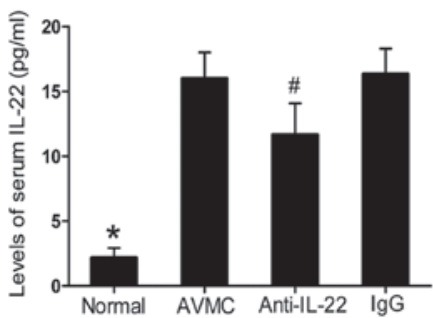

C

\section{$\mathbf{E}$}
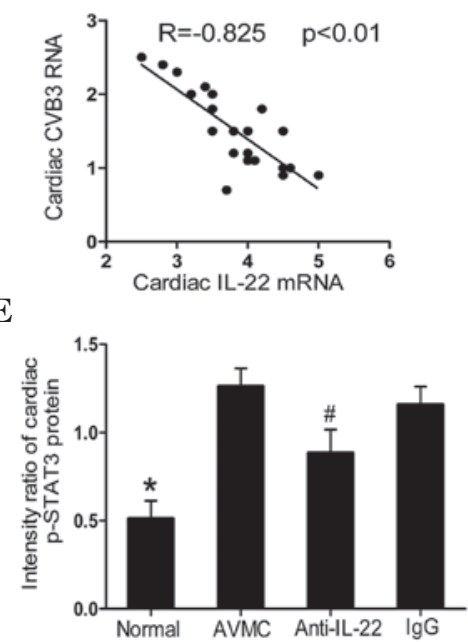

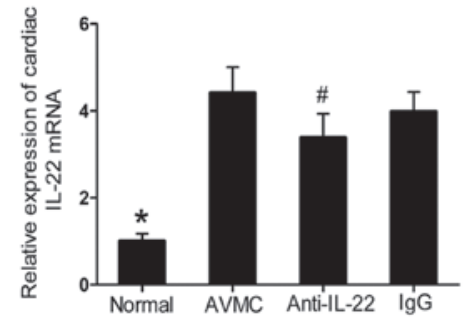

D

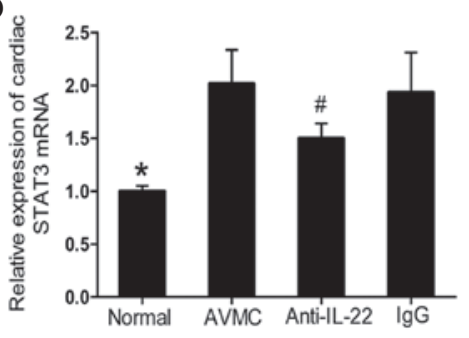

$\mathbf{F}$

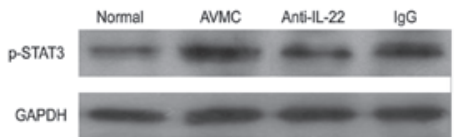

Figure 3. Neutralization of IL-22 in IL-17A $\mathrm{A}^{--}$mice decreased the levels of IL-22 and STAT3. (A) Results of the statistical analysis for the alteration of serum IL-22 protein levels, as investigated by ELISA. (B) The relative cardiac expression levels of IL-22, as analyzed by RT-PCR. (C) The correlation analysis of cardiac CVB3 RNA and cardiac IL-22 mRNA. (D and E) Results of the statistical analysis for the levels of cardiac STAT3 mRNA and STAT3 proteins, as measured by RT-PCR and western blot analysis, respectively. (F) Representative images for the levels of cardiac STAT3 proteins from each treated group. "P $<0.05$ versus the normal, AVMC and IgG groups. "P<0.01 versus the AVMC, anti-IL-22 and IgG groups. Values are presented as the mean \pm SD. IL, interleukin; STAT3, activator of transcription 3; RT-PCR, real-time polymerase chain reaction; CVB3, coxsackievirus B3; SD, standard deviation; GAPDH, glyceraldehyde phosphate dehydrogenase.
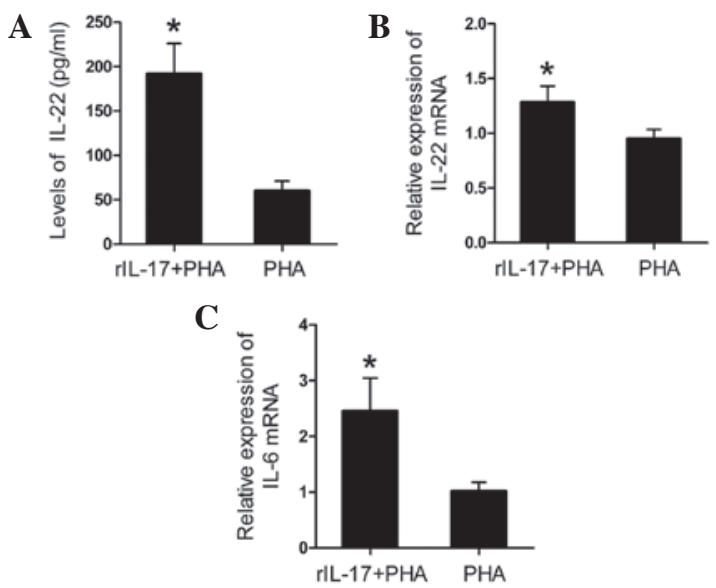

Figure 4. rIL-17 increased the production of IL-22 and IL-6. (A) The levels of IL-22 protein in culture supernatants, as measured by ELISA. (B and C) Results of IL-22 and IL-6 mRNA in cultured spleen lymphocytes, as analyzed by RT-PCR. ${ }^{\text {*P }}<0.01$ versus PHA groups only. Values are presented as the mean $\pm \mathrm{SD}$. rIL-17, recombinant interleukin-17; RT-PCR, real-time polymerase chain reaction; PHA, phytohaemafflutinin; SD, standard deviation.

$\mathrm{P}<0.05$; Fig. 3D-F). For IL-22 and STAT3, no significant difference was observed between the AVMC and IgG control groups.

rIL-17 increased the production of IL-22 and IL-6. To assess the effect of IL-17 on IL-22 production, spleen lymphocytes of AVMC from IL-17A ${ }^{-/-}$mice were incubated for $24 \mathrm{~h}$ with PHA and $25 \mathrm{ng} / \mathrm{ml}$ rIL-17 (R\&D Systems). Compared with those cultured with PHA only, data showed that the addition of rIL-17A to spleen lymphocyte cultures resulted in a significantly increased level of the IL-22 protein in culture supernatants and an upregulation of IL-22 mRNA in spleen lymphocytes (Fig. 4A and B; all $\mathrm{P}<0.01$ ). Furthermore, a significant increase in the mRNA expression levels of IL-6 was observed in the rIL-17A + PHA group in comparison with the PHA only group (Fig. $4 \mathrm{C} ; \mathrm{P}<0.01$ ).

\section{Discussion}

The secretion of numerous proinflammatory or protective cytokines is important in the pathogenesis of AVMC (4-6). Our previous study demonstrated that IL-17A and IL-22 responses were developed in CVB3-induced AVMC and characterized the myocardium-protective and antiviral roles of IL-22 in the presence of IL-17A (18). Enhanced co-expression of these two cytokines suggested that they may have a functional interaction. Studies conducted on the mouse model of intestinal intracellular parasites showed that the concurrent neutralization of IL-17A and IL-22 resulted in a reduction in infection-induced body weight loss, while the neutralization of IL-22 alone had no effect on body weight loss (21). Furthermore, Liang et al and Aujla et al observed synergy between IL-22 and IL-17A after infection with the pulmonary pathogen $K$. pneumonia, 
which promoted the production of inflammatory mediators and antimicrobial peptides (22) and contributed to the host defense after pulmonary infection (23). However, administration of exogenous IL-22 alone was not enough to promote neutrophil recruitment to the airway (24). On the basis of these results, it is possible that IL-17A contributes to the tissue-protective and antiviral properties of IL-22 in AVMC, therefore, we carried out the present study using IL-17A knockout mice.

Notably, in the present study, neutralization of IL-22 in the absence of IL-17A improved measures of the severity of AVMC, which was verified by lower values of HW/BW and pathological scores of heart sections and the decreased production of cardiac proinflammatory cytokines IL-6 and TNF- $\alpha$. These results and those from our previous studies (18) indicate that IL-22 appears to confer anti-inflammatory properties in a murine model of AVMC in the presence of IL-17A, whereas in the absence of IL-17A, IL-22 was no longer protective and instead conferred a proinflammatory and pathological outcome. By contrast, previous observations have shown that bleomycin induces acute tissue damage and airway inflammation (17), which indicates that IL-17A and IL-22 acted synergistically to promote inflammation, while IL-22 had tissue-protective functions in the absence of IL-17A. Our experiment demonstrates opposite data, where IL-17A prevented the proinflammatory properties and promoted the tissue-protective functions of IL-22, adding another layer of complexity to these cytokines. The first possible explanation for these observations may be that IL-17R and IL-22R expression are not overlapped. IL-17R is expressed in the tissues and cells of immune system $(25,26)$ and IL-17 activates T cells and other immune cells to produce a variety of cytokines, chemokines and cell adhesion molecules (27). By contrast, IL-22R is expressed in the tissues but is absent from cells of a hematopoetic origin. Thus, IL-22 acts as a middle-man between the immune system and its environment (8). The presence or absence of direct immune response activation by IL-17 may determine whether IL-22 alleviates or exacerbates the severity of AVMC. Secondly, STAT3, the important downstream signal protein of IL-22 (8-10), regulates a wide range of biological processes (28). In addition to our published data (6), the detection of enhanced levels of IL-22 and STAT3 in mice infected with CVB3 and the blockade of IL-22 causing a decrease in the amount of STAT3 in the present study suggests the importance of the IL-22/STAT3 pathway in the pathogenesis of AVMC. A number of studies have demonstrated the complex interactions between STAT3 and the downstream signal molecules of IL-17, including NF- $\kappa \mathrm{B}$ (29). This interplay between IL-17A and IL-22 signaling pathways may regulate the production of inflammatory cytokines, including IL-6 and TNF- $\alpha$, to determine the balance between pathological versus tissue-protective outcomes. Therefore, although further investigation is required, cytokine receptors and the signaling pathways of IL-17A and IL-22 may affect the functional properties of IL-22 and provide possible explanations for the distinct roles of IL-22 in murine models of AVMC.

Notably, cardiac CVB3 RNA was correlated negatively with the cardiac IFN- $\gamma$ and IL-22 mRNA and the upregulation of viral replication was observed in the anti-IL-22 Ab group. Additionally, we identified a lower amount of cardiac IFN- $\gamma$, the vital Th1 cell cytokine, in the anti-IL-22 Ab group, which is consistent with our earlier observation that the number of IL-22-producing Th22 cells was correlated positively with the number of IFN- $\gamma$-producing Th1 cells in mice infected with CVB3 (18). Th1 responses have been demonstrated to protect against viral replication and prevent chronic myocarditis/DCM and increase acute inflammation, particularly in males (30). Thus, the decreased production of the IFN- $\gamma$ gene, which may be modulated by the IL-22/STAT3 pathway, is a possible explanation for our observation that the enhancement of viral replication is followed by a decrease in acute cardiac inflammation, rather than an increase in myocarditis. These results also suggest that cardiac inflammation is not positively correlated with viral replication, since either virus-specific or immune responses also contribute to myocarditis. For instance, T-cell-deficient mice develop minimal cardiac injury despite high virus titers in the heart $(30,31)$. Together with our earlier studies, results of the present study indicate that IL-22 has an important antiviral function in AVMC microenvironmental conditions, independent of IL-17A.

Our published studies have demonstrated a positive correlation between IL-22-producing Th22 and IL-17-producing Th17 cells in WT mice (18). With regard to the serum levels of IL-22 in mice infected with CVB3, we observed lower amounts of IL-22 in IL-17A ${ }^{-/}$mice compared with WT mice (18). Data indicated that IL-17 may contribute to the production of IL-22 in AVMC in vivo. Therefore, we investigated the contribution of IL-17 to IL-22 in vitro and demonstrated that rIL-17 was able to enhance the mRNA expression and protein secretion of IL-22 in spleen lymphocytes, in addition to IL-6. The main explanation for this observation was that IL-17 induces the expression of IL-6, which is important for the differentiation and proliferation of IL-22-producing Th22 cells (32). Pertinent to our data, previous studies have observed increased IL-22 mRNA levels in the absence of IL-17A in mouse models of colitis (33) or decreased IL-22 mRNA levels in splenocyte cultures with the addition of exogenous IL-17A $(34,35)$. This discrepancy may be explained by a disease-specific difference in the role of IL-17A in regulating the production of IL-22.

A number of limitations should be noted in the present study. Firstly, the biological activity, affinity and/or potency of IL-22 antibodies in vivo are uncertain. The administered dose of anti-IL-22 Ab may not be able to completely antagonize the circulating IL-22 in vivo. Secondly, the exact mechanisms by which IL-17A regulates the proinflammatory or anti-inflammatory properties of IL-22 in AVMC remain unclear. Further studies with regard to this may be conducted in the future to clarify the complicated interactions among their downstream signaling pathways.

In conclusion, the present study furthers our previous findings and provides preliminary evidence for demonstrating the critical pathological and antiviral roles of IL-22 in AVMC, in the absence of IL-17A. To the best of our knowledge, in combination with our previous studies, our data provide the first demonstration that IL-17A is unable to govern the antiviral role of IL-22, although it is able to regulate the proinflammatory or tissue-protective properties and expression levels of IL-22, thereby determining the functional consequences of IL-22 in the pathogenesis of CVB3-induced AVMC. Our observation indicates that elucidation of the roles of IL-22 and the mechanisms of local cytokine dependency, including IL-17A, 
is likely to aid the understanding of the pathophysiology of IL-22-associated infections, inflammation and immune responses.

\section{Acknowledgements}

The study described in this manuscript was supported by grants from the National Natural Science Foundations of China (nos. 30960129 and 81260045). We would like to thank Dr Jiao Lan, Zoujiu Liang and Qiguang Huang for their technical assistance.

\section{References}

1. Dennert R, Crijns HJ and Heymans S: Acute viral myocarditis. Eur Heart J 29: 2073-2082, 2008.

2. Gupta S, Markham DW, Drazner MH and Mammen PP: Fulminant myocarditis.Nat Clin Pract Cardiovasc Med 5: 693-706, 2008

3. Cooper LT Jr: Myocarditis. N Engl J Med 360: 1526-1538, 2009

4. Fairweather D and Rose NR: Coxsackievirus-induced myocarditis in mice: a model of autoimmune disease for studying immunotoxicity. Methods 41: 118-122, 2007.

5. Yuan J, Yu M, Lin QW, Cao AL, Yu X, Dong JH, Wang JP, Zhang JH, Wang M, Guo HP, Cheng X and Liao YH: Th17 cells contribute to viral replication in coxsackievirus B3-induced acute viral myocarditis. J Immunol 185: 4004-4010, 2010.

6. Yang F, Wu WF, Yan YL, Pang Y, Kong Q and Huang YL: Expression of IL-23/Th17 pathway in a murine model of Coxsackie virus B3-induced viral myocarditis. Virol J 8: 301, 2011.

7. Trifari S, Kaplan CD, Tran EH, Crellin NK and Spits H: Identification of a human helper $\mathrm{T}$ cell population that has abundant production of interleukin 22 and is distinct from $\mathrm{T}(\mathrm{H})-17, \mathrm{~T}(\mathrm{H}) 1$ and $\mathrm{T}(\mathrm{H}) 2$ cells. Nat Immunol 10: 864-871, 2009.

8. Sonnenberg GF, Fouser LA and Artis D: Border patrol: regulation of immunity, inflammation and tissue homeostasis at barrier surfaces by IL-22. Nat Immunol 12: 383-390, 2011.

9. Radaeva S, Sun R, Pan HN, Hong F and Gao B: Interleukin 22 (IL-22) plays a protective role in $\mathrm{T}$ cell-mediated murine hepatitis: IL-22 is a survival factor for hepatocytes via STAT3 activation. Hepatology 39: 1332-1342, 2004.

10. Ziesché E, Bachmann M, Kleinert H, Pfeilschifter J and Mühl H: The interleukin-22/STAT3 pathway potentiates expression of inducible nitric-oxide synthase in human colon carcinoma cells. J Biol Chem 282: 16006-16015, 2007.

11. Takahashi K, Hirose K, Kawashima S, Niwa Y, Wakashin H, Iwata A, Tokoyoda K, Renauld JC, Iwamoto I, Nakayama T and Nakajima H: IL-22 attenuates IL-25 production by lung epithelial cells and inhibits antigen-induced eosinophilic airway inflammation. J Allergy Clin Immunol 128: 1067-1076, 2011

12. Wang P, Bai F, Zenewicz LA, Dai J, Gate D, Cheng G, Yang L, Qian F, Yuan X, Montgomery RR, Flavell RA, Town T and Fikrig E: IL-22 signaling contributes to West Nile encephalitis pathogenesis. PLoS One 7: e44153, 2012.

13. Missé D, Yssel H, Trabattoni D, Oblet C, Lo Caputo S, Mazzotta F, Pène J, Gonzalez JP, Clerici M and Veas F: IL-22 participates in an innate anti-HIV-1 host-resistance network through acute-phase protein induction. J Immunol 178: 407-415, 2007.

14. Zenewicz LA, Yancopoulos GD, Valenzuela DM, Murphy AJ, Karow M and Flavell RA: Interleukin-22 but not interleukin-17 provides protection to hepatocytes during acute liver inflammation. Immunity 27: 647-659, 2007.

15. Huber S, Gagliani N, Zenewicz LA, Huber FJ, Bosurgi L, Hu B, Hedl M, Zhang W, O'Connor W Jr, Murphy AJ, Valenzuela DM, Yancopoulos GD, Booth CJ, Cho JH, Ouyang W, Abraham C and Flavell RA: IL-22BP is regulated by the inflammasome and modulates tumorigenesis in the intestine. Nature 491: 259-263, 2012.

16. Laurence A, O'Shea JJ and Watford WT: Interleukin-22: a sheep in wolf's clothing. Nat Med 14: 247-249, 2008

17. Sonnenberg GF, Nair MG, Kirn TJ, Zaph C, Fouser LA and Artis D: Pathological versus protective functions of IL-22 in airway inflammation are regulated by IL-17A. J Exp Med 207: $1293-1305,2010$
18. Kong Q, Wu W, Yang F, Liu Y, Xue Y, Gao M, Lai W, Pan X, Yan Y, Pang Y and Deng Y: Increased expressions of IL-22 and Th22 cells in the coxsackievirus B3-Induced mice acute viral myocarditis. Virol J 9: 232, 2012

19. Nakae S, Komiyama Y, Nambu A, Sudo K, Iwase M, Homma I, Sekikawa K, Asano M and Iwakura Y: Antigen-specific T cell sensitization is impaired in IL-17-deficient mice, causing suppression of allergic cellular and humoral responses. Immunity 17: 375-387, 2002.

20. Eriksson U, Ricci R, Hunziker L, Kurrer MO, Oudit GY, Watts TH, Sonderegger I, Bachmaier K, Kopf $M$ and Penninger JM: Dendritic cell-induced autoimmune heart failure requires cooperation between adaptive and innate immunity. Nat Med 9: 1484-1490, 2003.

21. Stange J, Hepworth MR, Rausch S, Zajic L, Kühl AA, Uyttenhove C, Renauld JC, Hartmann S and Lucius R: IL-22 mediates host defense against an intestinal intracellular parasite in the absence of IFN- $\gamma$ at the cost of Th17-driven immunopathology. J Immunol 188: 2410-2418, 2012.

22. Liang SC, Tan XY, Luxenberg DP, Karim R, DunussiJoannopoulos K, Collins M and Fouser LA: Interleukin (IL)-22 and IL-17 are coexpressed by Th17 cells and cooperatively enhance expression of antimicrobial peptides. J Exp Med 203: 2271-2279, 2006.

23. Aujla SJ, Chan YR, Zheng M, Fei M, Askew DJ, Pociask DA, Reinhart TA, McAllister F, Edeal J, Gaus K, Husain S, Kreindler JL, Dubin PJ, Pilewski JM, Myerburg MM, Mason CA, Iwakura Y and Kolls JK: IL-22 mediates mucosal host defense against Gram-negative bacterial pneumonia. Nat Med 14: 275-281, 2008.

24. Liang SC, Long AJ, Bennett F, Whitters MJ, Karim R, Collins M, Goldman SJ, Dunussi-Joannopoulos K, Williams CM, Wright JF and Fouser LA: An IL-17F/A heterodimer protein is produced by mouse Th17 cells and induces airway neutrophil recruitment. J Immunol 179: 7791-7799, 2007

25. Yao Z, Fanslow WC, Seldin MF, Rousseau AM, Painter SL, Comeau MR, Cohen JI and Spriggs MK: Herpesvirus Saimiri encodes a new cytokine, IL-17, which binds to a novel cytokine receptor. Immunity 3: 811-821, 1995.

26. Gaffen SL: Structure and signalling in the IL-17 receptor family. Nat Rev Immunol 9: 556-567, 2009.

27. Komiyama Y, Nakae S, Matsuki T, Nambu A, Ishigame H, Kakuta S, Sudo K and Iwakura Y: IL-17 plays an important role in the development of experimental autoimmune encephalomyelitis. J Immunol 177: 566-573, 2006.

28. Dauer DJ, Ferraro B, Song L, Yu B, Mora L, Buettner R, Enkemann S, Jove R and Haura EB: Stat3 regulates genes common to both wound healing and cancer. Oncogene 24: 3397-3408, 2005

29. Bollrath J and Greten FR: IKK/NF-kappaB and STAT3 pathways: central signalling hubs in inflammation-mediated tumour promotion and metastasis. EMBO Rep 10: 1314-1319, 2009.

30. Fairweather D, Stafford KA and Sung YK: Update on coxsackievirus B3 myocarditis. Curr Opin Rheumatol 24: 401-407, 2012.

31. Woodruff JF and Woodruff JJ: Involvement of T lymphocytes in the pathogenesis of coxsackievirus B3 heart disease. J Immunol 113: 1726-1734, 1974.

32. Duhen T, Geiger R, Jarrossay D, Lanzavecchia A and Sallusto F: Production of interleukin 22 but not interleukin 17 by a subset of human skin-homing memory T cells. Nat Immunol 10: 857-863, 2009.

33. O'Connor W Jr, Kamanaka M, Booth CJ, Town T, Nakae S, Iwakura Y, Kolls JK and Flavell RA: A protective function for interleukin 17A in T cell-mediated intestinal inflammation. Nat Immunol 10: 603-609, 2009.

34. Smith E, Stark MA, Zarbock A, Burcin TL, Bruce AC, Vaswani D, Foley P and Ley K: IL-17A inhibits the expansion of IL-17A-producing T cells in mice through 'short-loop' inhibition via IL-17 receptor. J Immunol 181: 1357-1364, 2008.

35. von Vietinghoff S and Ley K: IL-17A controls IL-17F production and maintains blood neutrophil counts in mice. J Immunol 183: 865-873, 2009. 